\section{Antibacterial Action of Two Bacterial Products of Known Structure}

THE importance of inhibitory compounds in normal living systems, as distinct from their artificial introduction for example, as therapeutic agents, is being confirmation of the structure of Kögl and Postowsky ${ }^{5}$ was also found inhibitory, but to a lesser degree. Pyocyanin is already known to be inhibitory to bacterial growth and metabolism ${ }^{6}$. Thus the three known types of naturally occurring phenazine compounds, which are all bacterial pigments, can be of

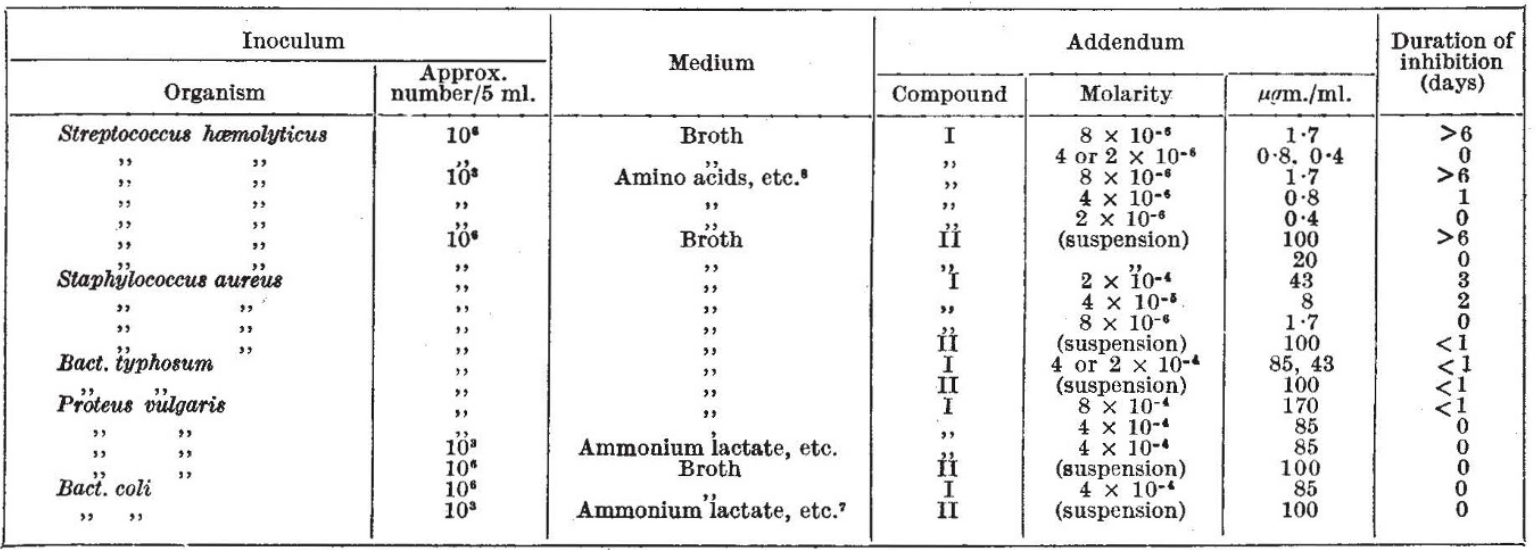

increasingly realized. In particular, substances have been isolated from certain micro-órganisms which inhibit the growth of other species (for detailed references see Waksman and Woodruff ${ }^{1}$ ). The structures of the majority of these compounds are not yet known, and in view of their importance as possible therapeutic agents or as models for such agents, the following results with two bacterial pigments of known composition are given.

The pigment of Chromobacterium iodinum was isolated and shown to be the N.N'-dioxide of a dihydroxyphenazine (probably $\mathrm{I}$ ) in $1938 .^{2}$<smiles>O=[n+]1c2ccccc2n([O-])c2ccc(O)c(O)c21</smiles>

I<smiles>CN1c2ccccc2Nc2c(C(N)=O)cccc21</smiles>

II
In connexion with other work in this laboratory, its effect on the growth of Bact. coli and Streptococcus hoemolyticus was recently investigated. The compound was found differentially inhibitory to a marked degree, and its effect on the growth of one strain each of other organisms was briefly surveyed.

It is seen that approximately $2 \mu \mathrm{gm} . / \mathrm{ml}$. of the pigment prevents visible growth of $S$. hoemolyticus in liquid media ; this inhibitory power is of the order of those recorded for the more active of the natural inhibitory substances. Like other substances, its action is greatest against the Gram-positive organisms investigated; the order of susceptibility of the organism is also that of increasing nutritional complexity. Inhibition was also exhibited on solid media : $2 \mu \mathrm{gm}$. of the pigment prevented growth of $S$. hoemolyticus within a radius of $1 \mathrm{~cm}$. In growth, Chr. iodinum can produce $100 \mu \mathrm{gm}$. of pigment per sq. $\mathrm{cm} .^{2}$.

A synthetic specimen of chlororaphin (II, formulated as a phenazyl ${ }^{3}$ ) which was prepared in $1934^{4}$ in functional value to the organisms producing them, by antagonizing the growth of competing organisms.

HenRy McIlwaIN.

(Leverhulme Research Fellow.)

Department of Bacterial Chemistry

(Medical Research Council),

The University,

Sheffield, 10.

Nov. 1

1 Waksman, S. A., and Woodruff, H. B., J. Bact., 40, 581 (1940) 42, 231 (1941).

${ }^{2}$ Clemo, G. R., and McIlwain, H., J. Chem. Soc., 479 (1938).

MeIlwain, H., J. Chem. Soc., 1704 (1937).

- Clemo, G. R., and McIlwain, H., J. Chem. Soc., 1991 (1934).

- Kögl, F., and Postowsky, J. J., Liebigs Ann., 480, 280 (1930)

- Schoental, R., Brit. J. Exp. Path., 22, 137 (1941).

"Fildes, P., Brit. J. Exp. Path., 19, 239 (1938).

- MeIlwain, H., Brit. J. Exp. Path., 21, 25 (1940).

\section{X-Ray Diffuse Reflexions from Sodium and Lithium in Relation to Elastic Anisotropy}

WE have photographed the diffuse X-ray reflexions from a number of single crystals of lithium and of sodium at various temperatures. Both show beautiful and elaborate patterns of spots and streaks, which are temperature-sensitive but not structure-sensitive.

Dr. Jahn has recently ${ }^{1}$ given an expression for the coherent diffuse scattering from a cubic crystal, based on the Faxén-Waller theory of thermal vibrations. He has applied the formula to sodium, using the known values of the elastic constants to predict the exact detail of the diffusely reflecting region around each reciprocal lattice point. One significant consequence of the theory is that for an elastically anisotropic cubic crystal (that is, when $c_{11}-c_{12} \gtrless 2 c_{44}$ ) the distribution of reflecting power is different for different reciprocal lattice points while, other things being equal, the intensity at a given distance from any lattice point varies inversely with the absolute values of the elastic constants. A soft, elastically anisotropic substance of simple structure, such as sodium, is therefore ideal for the purpose of testing 